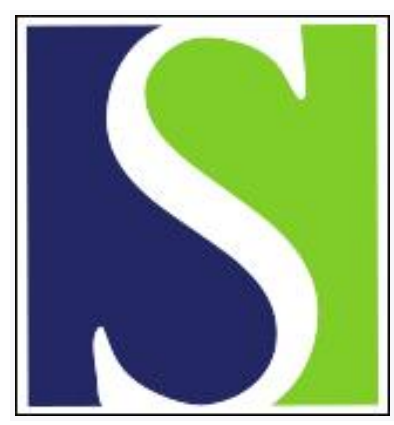

Scand J Work Environ Health 1987;13(3):258-260

https://doi.org/10.5271/sjweh.2053

Issue date: Jun 1987

\title{
Respiratory cancer among soap production workers.
}

by Forastiere F, Valesini S, Salimei E, Magliola ME, Perucci CA

This article in PubMed: www.ncbi.nlm.nih.gov/pubmed/3616557

\section{(c) (i)}




\title{
Respiratory cancer among soap production workers
}

\author{
by Francesco Forastiere, MD, ${ }^{1}$ Serena Valesini, BSc, ${ }^{1}$ Enrico Salimei, MD, ${ }^{2}$ \\ M Elisabetta Magliola, BSc, ${ }^{1}$ Carlo A Perucci, MD ${ }^{1}$
}

\begin{abstract}
FORASTIERE F, VALESINI S, SALIMEI E, MAGLIOLA ME, PERUCCI CA. Respiratory cancer among soap production workers. Scand J Work Environ Health 13 (1987) 258-260. Employment in the soap production industry in Italy has entailed some exposure to sulfuric acid vapors and nickel dusts, both agents under suspicion of being carcinogenic for the respiratory tract. A mortality study, together with an incidence study for laryngeal cancer, has been conducted among 361 men with a minimum employment of one year in soap production. Mortality from all causes was lower than expected, but lung cancer and laryngeal cancer deaths were increased, although without statistical significance. Five new laryngeal cancer cases were detected during the study period, while about one was expected. All the men with respiratory cancer had been working for several years, and the latency time was greater than 10 years. Even though the mechanism of a causal link is difficult to assess, the possibility of a carcinogenic effect of sulfuric acid is suggested.
\end{abstract}

Key terms: cohort study, epidemiology, laryngeal cancer, nickel, occupational exposure, respiratory cancer, sulfuric acid.

The possible role for some lifestyle (cigarette and alcohol consumption) and occupational (asbestos, nickel, isopropyl alcohol) exposures in laryngeal cancer occurrence has been already pointed out $(3,4)$. Sulfuric acid vapors have been recently hypothesized as a risk factor for such tumors $(1,5)$. We would like to add some epidemiologic evidence from a small factory in central Italy.

A compensation claim for occupational laryngeal cancer was brought to the attention of one of us (ES) for medical review. The worker had been working for a long time in a soap production plant entailing some exposure to sulfuric acid and nickel dusts. Local trade union members were interviewed and "too many cancers" were postulated together with very poor work conditions. After a review of the environmental data available, a cohort study was deemed worthwhile, given the peculiar exposure in the workplace.

Both mortality data and laryngeal cancer incidence rates were gathered for an epidemiologic evaluation.

\section{Subjects and methods}

The factory, located in central Italy (province of Frosinone), produces a solid soap used primarily for laundry purposes. It has been operating since 1938, and the production process was almost unchanged until 1977. Raw oils and fats were heated in the presence of sulfuric acid to obtain free fatty acids and glycerol.

\footnotetext{
I Epidemiological Unit, Latium Regional Health Authority, Rome, Italy.

2 Local Health Unit FR/4, Frosinone, Italy.
}

Reprint requests to: Dr Forastiere, Osservatorio Epidemiologico Regionale, Via G Carducci, 4, I-00187 Rome, Italy.
Fatty acids were hydrogenated, with nickel powder as a catalyst, and neutralized with soda to obtain soap. Sulfuric acid was, again, used to recuperate fatty acids from the waste water.

Airborne measurements were first conducted in 1974. Sulfuric acid vapors were present in the area of hydrolisis and saponification, the concentrations ranging from 0.64 to $1.12 \mathrm{mg} / \mathrm{m}^{3}$ (OSHA TWA = $\left.1.00 \mathrm{mg} / \mathrm{m}^{3}\right)$. As for other pollutants, soap powder, glycerol, and fatty acids were found in the atmosphere along with nickel and its compounds (up to 0.07 $\left.\mathrm{mg} / \mathrm{m}^{3}\right)$ and mineral oils $\left(1.2 \mathrm{mg} / \mathrm{m}^{3}\right)$.

Three hundred and sixty-one men, drawn from the company records, were enrolled in a cohort encompassing blue-collar workers active on 1 January 1964 , or subsequently employed until 1972, and with at least one year of employment.

For each subject the vital status was obtained, along with the cause of death of the decedents, for the period 1 January 1969-30 June 1983 from the registry offices of either the last municipality of residence or the place where the death occurred. Causes of death were coded according to the eighth revision of the International Classification of Diseases. A total of 347 subjects could be traced $(96 \%)$, while 11 were lost and 3 had emigrated.

Laryngeal cancer incidence was also assessed for a shorter period (1 January 1972-30 June 1983) through a check of the discharge files of the ear, nose and throat departments of the four hospitals located in the province of Frosinone and in the three main hospitals in the city of Rome. The medical records provided relevant clinical features and previous smoking habits.

The expected numbers of deaths from specific causes were calculated applying the death rates of the province were the factory was located $(420000$ inhabi- 
tants), stratified by age (five-year classes) and calendar period (five-year classes), to the corresponding person-years of the cohort. Workers lost to follow-up were considered alive in the generation of the numbers of expected cases.

The only reference population available for cancer incidence data in Italy (Varese) is peculiar with respect to laryngeal cancer occurrence, showing one of the highest rates in Europe (6). Given such a poor situation with regard to comparison data, we deemed it worthwhile to calculate expected laryngeal cancer cases in the cohort according to different rates, ie, (i) laryngeal cancer incidence (by period, sex, and age) for the province of Frosinone estimated according to discharge diagnoses of the ear, nose and throat departments of the seven previously mentioned hospitals and (ii) incidence rates from cancer registers in southern Europe, ie, Geneva, Neuchatel, Saragozza, and Varese (6).

The standardized mortality ratio (SMR) values were computed along with the $95 \%$ confidence intervals (95\% CI) based on the assumption of a Poisson distribution of the observed cases.

\section{Results}

The person-years of observation were 4955 for the mortality study, whereas 3927 person-years were obtained for the laryngeal cancer incidence.

Less than the expected number deaths occurred for all causes (SMR 70, 95 \% CI $=47-100$ ), as well as for cause-specific mortality (table 1), apart from lung cancer (SMR 169, $95 \% \mathrm{CI}=55-386$ ), laryngeal cancer (SMR 230, $95 \% \mathrm{CI}=9-1143$ ), and ill-defined diseases (SMR 481, $95 \% \mathrm{CI}=97-1346)$, which were increased although not statistically significant.

Five new squamous laryngeal cancers (including the one death), all among previous smokers, were detected during the study period (table 2), while only from 0.72 to 1.44 were expected on the basis of the different reference rates; none of the confidence intervals of the SMR values included unity.

\section{Discussion}

The interpretation of these findings is difficult because of the small numbers, which do not allow a moredetailed analysis (ie, duration of exposure, time since first employment).

Regarding the mortality study, a rather strong "'healthy worker effect" seems to have been involved. The SMR for all causes was low (70). Such an effect could be partly due to the relatively young age of the cohort, as well as to the loss of the mortality experience of those employed and retired before 1964 .

A real excess risk for respiratory cancer (of both the upper and the lower tract) could have been concealed, since only the SMR values for such cancer deaths were
Table 1. Cause-specific mortality experience of the soap production workers. $(O=$ observed number of deaths, $E=$ ex pected number of deaths, SMR = standardized mortality ratio $95 \% \mathrm{Cl}=95 \%$ confidence interval).

\begin{tabular}{lrrrr}
\hline Causes of deatha & O & E & SMR & $95 \% \mathrm{Cl}$ \\
\hline All malignant & & & & \\
$\begin{array}{l}\text { neoplasms (140-209) } \\
\quad \text { Stomach cancer (151) }\end{array}$ & 1 & 11.2 & 71 & $31-139$ \\
$\quad \begin{array}{l}\text { Laryngeal cancer (161) } \\
\quad \text { Lung cancer (162) }\end{array}$ & 1 & 0.6 & 230 & $2-280$ \\
$\begin{array}{l}\text { Circulatory diseases } \\
\text { (390-459) }\end{array}$ & 15 & 17.5 & 86 & $48-1143$ \\
$\begin{array}{l}\text { Respiratory diseases } \\
\text { (460-519) }\end{array}$ & - & 3.1 & $\ldots$ & \\
$\begin{array}{l}\text { Diseases of the digestive } \\
\text { system (520-577) }\end{array}$ & 1 & 4.1 & 25 & $1-122$ \\
$\begin{array}{l}\text { Disease of the urinary } \\
\text { system (580-629) }\end{array}$ & 1 & 0.9 & 111 & $4-552$ \\
$\begin{array}{l}\text { III-defined diseases } \\
\text { (790-796) }\end{array}$ & 3 & 0.6 & 481 & $97-1346$ \\
Accidents (800-999) & 2 & 3.4 & 60 & $7-202$ \\
\hline \begin{tabular}{l} 
All causes (000-999) \\
\hline
\end{tabular} & 30 & 42.8 & 70 & $47-100$ \\
\hline
\end{tabular}

a Code of the International Classification of Diseases (eighth revision) is shown in parentheses.

Table 2. Some clinical and occupational features of the larynx cancer cases.

\begin{tabular}{lcccc}
\hline Case site & $\begin{array}{c}\text { Date at } \\
\text { diagnosis }\end{array}$ & $\begin{array}{c}\text { Age } \\
\text { (years) }\end{array}$ & $\begin{array}{c}\text { Time } \\
\text { since first } \\
\text { exposure } \\
\text { (years) }\end{array}$ & $\begin{array}{c}\text { Duration } \\
\text { of exposure } \\
\text { (years) }\end{array}$ \\
\hline 1 Larynx & & & & \\
$\quad$ unspecified & 1972 & 53 & 13 & 13 \\
2 Epiglottis & 1976 & 55 & 27 & 27 \\
3 Vocal cord & 1976 & 67 & 21 & 9 \\
4 Epiglottis & 1977 & 63 & 12 & 4 \\
5 Ventricular & 1980 & 64 & 29 & 24 \\
\hline bands & & & & \\
\hline
\end{tabular}

above unity and all of the deaths occurred 10 or more years after the first exposure.

An association between laryngeal cancer incidence and this workplace seems to be suggested by a risk three to five times greater than expected. Furthermore, given that, for all the cases, the latency period since first employment had been more than 10 years, a causal association seems more plausible.

A better reference population with regard to laryngeal cancer incidence was not available, and the use of cancer register data from other areas can be criticized. Nevertheless the excess risk persists even when the general population of Varese, which has one of the highest laryngeal cancer rates in Europe (6), is used as the reference population.

A possible confounding effect from smoking and alcohol consumption cannot be ruled out. However it is unlikely that such confounders could explain a relative risk above two (2). Furthermore there is no evidence from the mortality data of an excess rate of smoking- and alcohol-related diseases.

Chance alone could very well be the explanation of the observed excess, expecially since there were some preliminary suspicions of an elevated cancer risk. In addition we could not evaluate the possible role of 
other substances present in the workplace (ie, nickel, mineral oils, fatty acids) with respect to cancer induction.

Nevertheless the present findings, given previous data on the carcinogenicity of sulfuric acid in a pickling house (1) and in a refinery plant (5), call for further observations of the long-term effects of this substance.

\section{Acknowledgments}

We are indebted to Ms A Carboni and Ms C Pescatori for typing and editing the manuscript.

\section{References}

1. Ahlborg G, Hogstedt C, Sundell L, Aman CG. Laryngeal cancer and pickling house vapors. Scand J Work Environ Health 7 (1981) 239-240.
2. Axelson O. Aspects of confounding in occupational health epidemiology. Scand J Work Environ Health 4 (1978) 85-89.

3. Flanders WD, Lann CI, Rothman KJ, Fried MP. Work related risk factors for laryngeal cancer. Am J Epidemiol 119 (1984) 23-32.

4. Rothman KJ, Cann CJ, Flanders D, Fried MP. Epidemiology of laryngeal cancer. Epidemiol Rev (1980) 195 -209 .

5. Soskolne CL, Zeighami EA, Hanis NM, Kupper LL, Herrmann N, Amsel J, Mausner JS, Stellman JM. Laryngeal cancer and occupational exposure to sulfuric acid. Am J Epidemiol 120 (1984) 358-369.

6. Waterhouse J, Muir C, Shanmugara TK, Powerl J, ed. Cancer incidence in five continents. Volume 4. International Agency for Research on Cancer, Lyon 1982.

Received for publication: 4 July 1986 